\title{
Effects of Pilates and aqua fitness training on older adults' physical functioning and quality of life
}

\author{
Magdolna Vécseyné Kovách ${ }^{1}$, Judit Kopkáné Plachy², József Bognár², \\ Zsuzsanna Olvasztóné Balogh ${ }^{3}$, István Barthalos²
}

${ }^{1}$ Eszterházy Károly College - Institute of Sport Sciences, Eger, ${ }^{2}$ Semmelweis University Faculty of Physical Education and Sport Sciences, Budapest, ${ }^{3}$ University of Debrecen, Faculty of Child and Adult Education, Hajdúböszörmény, Hungary

\begin{abstract}
Study aim: To measure the effects of Pilates and aqua fitness training on functional fitness and quality of life in older individuals.

Material and methods: A total of 54 participants $(\mathrm{M}=66.4 \pm 6.2$ years $)$ from a club for retired people in Eger, Hungary, were randomly assigned to 3 groups: one did Pilates 3 times/week $(n=22)$; one did aqua fitness 3 times/week $(n=17)$; and a control group $(\mathrm{n}=15)$. The Fullerton Functional Fitness Test (FFFT) was used to measure functional fitness pre - and post-program. Quality of life was measured by WHO's quality of life questionnaire (WHOQOL).

Results: In the FFFT, significant improvement was found in 5 out of 7 variables: lower and upper body strength, lower body flexibility, physical mobility (especially dynamic balance), and aerobic endurance by the Pilates group. Shoulder flexibility improved significantly in the Aqua fitness group. Lower body strength improved in the control group. BMI did not change significantly in any of the groups. WHOQOL showed improvement in perception and autonomy in the Pilates group; sociability in the Aqua group. The between-subject analyses yielded a significant main effect of the experimental group $\mathrm{F}_{(1,52)}=4367(\mathrm{p}<0.001)$.

Discussion: A 6-month intervention program is an appropriate tool to improve overall physical performance of healthy, inactive older adults, regardless of the type of exercise concerning Pilates or Aqua fitness, but might improve only some aspects of QOL. There is a strong need for well-designed intervention programs for the elderly.
\end{abstract}

Key words: Older adults - Intervention program - Functional fitness - Quality of life

\section{Introduction}

Maintaining functional fitness and quality of life (QOL) throughout life is of crucial importance. Regular physical activity is one of the most important self-care behaviors that can contribute to healthy aging, physical fitness, and QOL throughout the entire lifespan $[3,8,9$, 19]. In this text, functional fitness is defined as having the physiological capacity to perform everyday actions safely and independently without undue fatigue [22].

Many studies that have focused on the relationship between regular physical activity and healthy aging, its effects on physical performance, and cognitive and psychological functioning in older adults have been based on intervention programs [4, 28, 29]. Most of these studies show significant improvement in old sample's physical functioning as the result of becoming physically active for a certain period of time.
A pilot study conducted by Waters and Hale [28], which consisted of a 12-week Aquatic exercise program, measured gait and balance changes in older adults $(70.55 \pm 3.6$ years). It provided evidence of the potential benefits of Aqua aerobics on dynamic balance. Participants reported a range of perceived physiological and psychical advantages. A longer intervention and follow-up was recommended to determine additional functional and other outcomes [28].

The dependence of psychological well-being (including QOL) on physical changes is not always so clear $[4,13,28,29]$. Neither Dunn et al. [7] in their narrative review nor Craft and Landers in their meta-analytic review [6], both of which concerned effects in the general population, were able to provide evidence of such dependence. Arent et al. [2] reviewed 32 studies and concluded that exercise is associated with improved mood in the elderly. Yet Spirduso and Cronin [25] in their qualitative review on older adults proposed that 
physical activity might enhance quality of life without improving cardiorespiratory status. They postulated that the act of exercising might be beneficial in itself. A literature review conducted by Rejeski et al. [21] on the connection between PA and QOL indicated that a change in life satisfaction was often unrelated to changes in objective markers of fitness (e.g., aerobic power). QOL shows strong and direct relationship with health status. Health and functional status are 2 variables that are often found to explain QOL of older adults. In a review on perceived health of older adults and QOL, Moore et al. [11] reported that in 11 out of 17 studies, there was a strong positive relationship between these two variables. Raphael et al. [20] also reported a positive relationship between QOL and health status of older adults. In a study that took place in Japan, the relationship between functional fitness and life satisfaction was assessed from the perspective of QOL of 123 older individuals $(\mathrm{M}=74.3 \pm 5.4$ years $)$. The analysis revealed no overall correlation between the total fitness and total life satisfaction scores, but some of the life satisfaction factors were significantly related to some functional fitness items $(\mathrm{p}<0.01)$. The results suggested that it is important that older people maintain their functional fitness in order to have a high quality of life [5].

Interventions aimed to develop quality of life and cognitive function besides motor skills, many times apply a so-called mind and body method, in which the control of the mind on each body movement has to be present at all times. Pilates and yoga are the best examples $[10,14]$. Oken and his colleagues conducted a 6-month trial of yoga to determine the effects on cognitive function, fatigue, mood, and QOL in seniors. No effects were indicated in any of the cognitive or alertness outcome measures, but the program did show improvement in a number of QOL measures and physical measures [14]. An 8-week Pilates study that aimed to evaluate the effects of the method on personal autonomy, static balance and quality of life (measured by WHOQOL-OLD) in 52 healthy elderly females found that the Pilates method can offer significant improvement in personal autonomy, static balance, and quality of life [23].

According to the ACSM and AHA recommendations, older adults need to be active at least 3 days each week in order to promote and maintain health [12]. Not only are aerobic exercise and resistance training important parts of an overall fitness program, but flexibility exercise and balance training are as well $[1,12,16]$. In program planning, these recommendations were taken into consideration regarding exercise type, dose, and participation rate. Both Pilates and Aqua fitness exercises fit well with these guidelines.
In the Hungarian sport scientific research, the mature generation is a relatively understudied age group. More importantly, there have been very few structured intervention programs that have focused on how physical activity influences fitness and quality of life. To fill this gap, our main purpose was to present the effects of a 6-month modified Pilates training and Aqua fitness training on physical performance and quality of life in a healthy, older population. In addition, we aimed to reveal which of the 2 types of exercises - Pilates or Aqua-fitness - had stronger effects on the aforementioned variables.

\section{Methods}

\section{Participants}

Participants were members of a club in Eger for the retired. All club members whose state of health allowed and were willing to participate were involved $(\mathrm{N}=54)$. They were all informed thoroughly about the details of the intervention program. All participants supplied their written consents to participate; the study was approved by the local Committee of Ethics. Those participants who missed more than $20 \%$ of the classes were not taken into account in the results. In our opinion (and according to the aforementioned ACSM/AHA recommendations), physical activity in those cases cannot be regarded regular.

Participants' mean age was $66.4 \pm 6.2$ years; $76.4 \%$ were women. Half of the sample had a college or university degree (50\%), $40.7 \%$ had secondary (high school) degrees, and $9.3 \%$ had an elementary education only. Participants were randomly assigned to 3 groups. The first group $(\mathrm{n}=22, \mathrm{M}=66.6 \pm 5.5$ years, $\mathrm{n}=17$ females $)$ did a basic Pilates mat workout 3 times per week for 60 minutes. The second group $(\mathrm{n}=17, \mathrm{M}=67.9 \pm 6.9$, $\mathrm{n}=13$ females) did Aqua-fitness 3 times per week for 60 minutes. The third one was the control group $(\mathrm{n}=15$, $\mathrm{M}=64.6 \pm 6.2, \mathrm{n}=11$ females).

None of the participants in our sample did regular physical activity prior to the program (regular physical activity was defined as exercising at least for 30 minutes 3 times per week). All participants filled out a form that they took part in the program on their own risk (waiver) and had a certificate by their medical practitioner that they were allowed to participate.

\section{Types of exercises}

Pilates - due to participants' previous illnesses, some exercises were excluded from the Pilates exercises, especially those exercises resulting in high chest pressure, burden the lumbar-sacral junction, and trunk rotational exercises. Basic Pilates mat exercises were used. 
Aqua fitness - shallow water training was applied in our intervention, where the feet touch the bottom of the pool and water does not exceed shoulder level [18].

\section{Procedures}

Three experts were responsible for taking measurements before and after the program and to run the classes for 6 months. These experts were qualified physical education teachers and physiotherapists. Participants completed the survey instruments individually. The intervention ran 3 times per week for $60 \mathrm{~min}$ utes for 6 months.

\section{Assessments}

1. The Fullerton Functional Fitness Test was chosen to measure the changes in those physiological attributes that support behavior needed to perform everyday activities required for independent living:

- Chair Stand Test - to assess lower body strength: total number of stand ups from a chair in 30 seconds.

- Arm Curl Test - to assess upper body strength: total number of arm curls with a dumbbell in the hand for 30 seconds; $1 \mathrm{~kg}$ dumbbell for females and $2 \mathrm{~kg}$ dumbbell for males.

- Walk Test - to assess aerobic endurance: the total number of meters walked around a measured course in 6 minutes $(\mathrm{m})$.

- Back Scratch Test - to assess upper body (shoulder) flexibility: the distance between middle digits at the back $(+,-\mathrm{cm})$.

- Chair Sit and Reach Test - to assess lower body (primarily hamstring) flexibility: the distance between big toe an tip of middle digits $(+,-\mathrm{cm})$.

- 8-Foot Up and Go Test - to assess physical mobility (speed, agility, and dynamic balance): time needed to stand up from a chair, bypass a buoy, and sit down.

- Body mass index (BMI, $\mathrm{kg} / \mathrm{m}^{2}$ ) were assessed with Inbody-230 body composition analyzer.
This test was developed especially for older adults through research at the lifespan Wellness Clinic at California State University, Fullerton. It is easy to administer, safe for older participants, and requires minimal equipment, time, and space [22].

2. Quality of life was measured by WHOQOL-OLD, a 24-item, 6-facet test, developed from WHOQOL to assess quality of life of older adults. The 24 questions were grouped around six main topics: autonomy, sociability, attitudes towards death, activities of past, present and future, perception and intimacy. This instrument has previously shown that it produces reliable and valid scores with a similar sample [26].

\section{Statistical Analysis}

Data were analyzed using the Statistical Package for Social Sciences for Windows, version 17. Characteristics of the sample were described by descriptive statistics and frequencies. Differences between preand post-measured data were analyzed by paired sample $t$-test. Repeated measures ANOVA was used to test the effect of the type of group and time on variables and the interaction between time and group effects. All measures were assessed for normality of distribution. Mauchly's test was completed as the prerequisite of repeated measures ANOVA. Scheffé's post hoc test was used to discover differences between group results. The level fo significance $\alpha=0.05$ was adopted.

\section{Results}

1.Fullerton Functional Fitness Test - (Table 1).

Significant differences were found in 5 of the 7 variable pairs at the Pilates group. Lower $(\mathrm{t}=12$, $\mathrm{p}<0.001)$ and upper body strength $(\mathrm{t}=10, \mathrm{p}<0.001)$, lower body flexibility $(\mathrm{t}=7, \mathrm{p}<0.001)$, physical mobility $(\mathrm{t}=7, \mathrm{p}<0.001)$ (dynamic balance), and

Table 1. Mean values $( \pm S D)$ of the Fullerton fitness test recorded in older adults before (Pre) and after (Post) the experiment

\begin{tabular}{|c|c|c|c|c|c|c|}
\hline \multirow[b]{2}{*}{ Variable } & \multicolumn{2}{|c|}{ Control $(\mathrm{n}=15)$} & \multicolumn{2}{|c|}{ Pilates $(n=22)$} & \multicolumn{2}{|c|}{ Aqua $(\mathrm{n}=17)$} \\
\hline & Pre & Post & Pre & Post & Pre & Post \\
\hline Chair stand & $19.8 \pm 4.9^{* *}$ & $22.3 \pm 5.9^{*}$ & $16.2 \pm 2.9$ & $23.6 \pm 3.3^{* * *}$ & $16.1 \pm 4.4$ & $21.6 \pm 3^{* * *}$ \\
\hline Arm curl & $28.5 \pm 5.3$ & $27.9 \pm 3.4$ & $23.7 \pm 4.2$ & $32.1 \pm 4.2^{* * *}$ & $21.7 \pm 4.3$ & $29.5 \pm 3.15^{* * *}$ \\
\hline Back stratch & $7.3 \pm 8.45$ & $8 \pm 10.4$ & $-.86 \pm 6.5$ & $-3.4 \pm 5.6$ & $1.3 \pm 8.4$ & $-2.7 \pm 8^{*}$ \\
\hline Sit and reach & $7.7 \pm 7.3$ & $4.9 \pm 8.1$ & $4.9 \pm 8.7$ & $-8.3 \pm 4.6^{* * *}$ & $5 \pm 8.7$ & $-8.3 \pm 6.8^{* * *}$ \\
\hline 8 Foot Up and go & $5.4 \pm 0.6$ & $5.6 \pm 0.8$ & $5.9 \pm 0.8$ & $5 \pm 0.5^{* * *}$ & $6.5 \pm 1.2$ & $5.45 \pm 0.9 * *$ \\
\hline Six minute walk & $418 \pm 71.8$ & $416 \pm 63.2$ & $406.5 \pm 83$ & $537.4 \pm 54.3^{* * *}$ & $427.5 \pm 73.6$ & $525.3 \pm 84.4^{* * *}$ \\
\hline BMI & $28.9 \pm 5.1$ & $27.7 \pm 3.9$ & $26.4 \pm 3.0$ & $25.9 \pm 3.0$ & $26.9 \pm 2.3$ & $26 \pm 2.2$ \\
\hline
\end{tabular}

Significantly different from the respective 'Pre' value:* $\mathrm{p}<0.05 ;{ }^{* *} \mathrm{p}<0.01 ;{ }^{* * *} \mathrm{p}<0.001$; 
aerobic endurance $(t=-6.99, \mathrm{p}<0.001)$ improved significantly as the result of the 6-month program. Shoulder flexibility and BMI did not change significantly. For the Aqua group, all 5 items, plus upper body flexibility $(\mathrm{t}=2.9, \mathrm{p}<0.05)$, changed significantly. Only BMI did not change significantly. Lower body strength improved in the control group $(\mathrm{t}=3.4$, $\mathrm{p}<0.01)$.

2.WHOQOL-OLD questionnaire - (Table 2).

Autonomy $(\mathrm{t}=3.25, \mathrm{p}<0.01)$ and perception $(\mathrm{t}=-4.813, \mathrm{p}<0.001)$ in the Pilates group and sociability $(\mathrm{t}=-4.75, \mathrm{p}<0.001)$ in the Aqua group, as subscales of QOL, had improved significantly by the end of the program.

3. Results of the 2-way mixed ANOVA with repeated measures.

A 2-way mixed ANOVA with repeated measures was applied to test the effects of the 3 different interventions (control, Aqua, and Pilates) on FFFT and QOL items in two measures (pre-and post-program - time) and their interactions. Type of group - control, Aqua and Pilates - was the between-subjects factor. All the multivariate tests of significance suggested the presence of a main effect for group factor $(p<0.001)$; the presence of an interaction effect as multivariate tests rejected the null at $\mathrm{p}<0.05(\mathrm{p}<0.001)$. We conclude the presence of a group*time interaction.

The within-subject effects results showed a statistically significant main effect for the time factor $\mathrm{F}_{(1,52)}=66.2(\mathrm{p}<0.001)$ and a statistically significant group*time interaction effect $\mathrm{F}_{(2,52)}=18.6$ $(\mathrm{p}<0.001)$. The between-subject analyses yielded a significant main effect of the experimental group $\mathrm{F}_{(1,52)}=4367(\mathrm{p}<0.001)$. Scheffé's post hoc analysis revealed that performance of both the Aqua and Pilates groups $(\mathrm{p}<0.05)$ differed significantly from that of the control group.

\section{Discussion}

Both Pilates and Aqua-fitness workouts 3 times per week, conducted regularly for a half year, are appropriate means to improve overall physical performance needed for everyday life for inactive older adults and can contribute to maintaining aspects of quality of life. Aqua-fitness was more effective in the improvement of shoulder flexibility than Pilates, but no other difference could be supported in any of the motor tests between the 2 exercise groups. Other physical tests showed significant improvement in both exercising groups. It has to be mentioned that there was a significant improvement in one variable, in lower body strength in the control group. Some control group members reported that simply taking part in the pre-measurement motivated them to start being more active (e.g., walk more). That might account for the positive change.

It can be concluded that it basically doesn't matter which type of exercise is being practiced regarding upper, lower body strength, upper, lower body flexibility, dynamic balance and aerobic endurance, if it is practiced regularly and for enough of a time period. A Pilates program presented by Kloubec [10] demonstrated that exposure to Pilates exercise for 12 weeks for two 60-minute sessions per week was sufficient to promote statistically significant increases in abdominal endurance, hamstring flexibility, and upper-body muscular endurance. Participants did not demonstrate improvements in either posture or balance when compared with the control group. In our study, dynamic balance improved as well, as the program was longer and sessions were more frequent. The program was not long enough, however, to result in changes in overall life quality. A more extensive program, in which participants' needs and interests are taken into greater

Table 2. Mean values ( $\pm \mathrm{SD}$ ) of the QOL-OLD questionnaire recorded in older adults before (Pre) and after (Post) the experiment

\begin{tabular}{lcccccc}
\hline & \multicolumn{2}{c}{ Control $(\mathrm{n}=15)$} & \multicolumn{2}{c}{ Pilates $(\mathrm{n}=22)$} & \multicolumn{2}{c}{ Aqua $(\mathrm{n}=17)$} \\
Variable & Pre & Post & Pre & Post & Pre & Post \\
\hline Perception & $10.4 \pm 2.4$ & $9.6 \pm 2.5$ & $8.9 \pm 1.4$ & $10.3 \pm 1.7^{* * *}$ & $10.1 \pm 1.3$ & $10 \pm 1.4$ \\
Autonomy & $14.3 \pm 2.5$ & $14.5 \pm 2.7$ & $15.55 \pm 2.5$ & $14.3 \pm 2.2^{* *}$ & $14.2 \pm 3.05$ & $14.7 \pm 2.2$ \\
Present, past & $14.2 \pm 2.2$ & $13.9 \pm 1.9$ & $14.2 \pm 1.8$ & $13.7 \pm 2.2$ & $14.2 \pm 2.8$ & $14.8 \pm 1.8$ \\
and fututre & $14.1 \pm 2.3$ & $14 \pm 2.2$ & $14.95 \pm 2.15$ & $15.55 \pm 1.9$ & $14.8 \pm 2.55$ & $16.3 \pm 2.2^{* * *}$ \\
Sociability & $10 \pm 5.6$ & $10.1 \pm 4.9$ & $10.7 \pm 4.2$ & $10.6 \pm 3.9$ & $9.6 \pm 3.4$ & $9.2 \pm 2.5$ \\
Death & $11.9 \pm 4.8$ & $11.7 \pm 4.3$ & $12.55 \pm 4.6$ & $13.1 \pm 3.7$ & $13.5 \pm 4.3$ & $14.4 \pm 3.5$ \\
Intimicy & & & & & & \\
\hline
\end{tabular}

Significantly different from the respective 'Pre' value: $\mathrm{p}<0.05$; $^{* *} \mathrm{p}<0.01 ;{ }^{* * *} \mathrm{p}<0.001$; 
consideration, may be more effective on the variables mentioned above.

In our pre-study conducted in Eger about regular physical activity habits of the target population, it was revealed that the characteristics of female and higher education level had a positive effect on PA habits [27]. Other studies have also shown that high levels education positively influences participation in regular physical activity $[15,24]$. It is recommended that in future studies more males and more older adults with lower education levels should be involved in the research.

Although nearly all markers of physical fitness improved significantly, only some aspects of quality of life were found to change as the result of the 6-month exercise program. This means that the improvement of objective markers of physical fitness does not necessarily mean positive change in life quality, as found by Rejeski et al. [21] in a literature review on the connection between PA and QOL. It has also been reported that individuals who participated in physical activities that they enjoyed reported the highest levels of life satisfaction $[17,21]$.

These results suggest that enjoyment may be a possible mediator of change in life satisfaction related to physical activity participation. In program planning, it may also be important to specify the type of program being conducted in order to influence participant quality of life.

Because the program is still successfully going on, we have made regular physical activity a part of these participants' everyday lives. Individual feedback about the program was also very positive - they enjoyed taking part in the program and reported a range of physiological and psychological benefits. Older adults deserve much more attention than they get in Hungary. This study clearly highlights the need for well-planned and professionally executed interventions to increase physical activity participation of older adults in the future in the country.

\section{References}

1. American College of Sports Medicine (1995) American College of Sports Medicine position stand on osteoporosis and exercise. Med. Sci. Sports Exerc., 27: i-vii.

2. Arent S.M., D.M. Landers, J.L. Etnier (2000) The effects of exercise on mood in older adults: A meta-analytic review. J. Aging Phys. Activity, 8: 407-430.

3. Brosse A.L., E.S. Sheets, H.S. Lett, J.A. Blumenthal (2002) Exercise and the treatment of clinical depression in adults: Recent findings and future directions. Sports Med., 32: 741-760.
4. Byfield C.L. (2001) Development and evaluation of a lifestyle physical activity intervention for obese sedentary women. Colorado State University, PhD Thesis 2001.

5. Chang M., H. Kim, R. Shigematsu, H. Nho, T. Nishijima, K. Tanaka (2001) Functional fitness may be related to life satisfaction in older Japanese adults. Int. J. Aging Hum. Dev., 53(1): 35-49.

6. Craft L.L., D.M. Landers (1998) The effect of exercise on clinical depression and depression resulting from mental illness: A meta analysis. J. Sport Exerc. Psychol., 20: 339-357.

7. Dunn A.L., M.H. Trivedi, H.A. O'Neal (2001) Physical activity dose-response effects on outcomes of depression and anxiety. Med. Sci. Sports Exerc., 33: S587-S597.

8. Evans W.J. (1999) Exercise training guidelines for the elderly. Med. Sci. Sports Exerc., 31(1): 12-17.

9. Keysor J.J., A.M. Jette (2001) Have we oversold the benefit of late-life exercise? J. Gerontol. A Biol. Sci. Med. Sci., 56A: M412-M423.

10. Kloubec J.A. (2010) Pilates for improvement of muscle endurance, flexibility, balance, and posture. J. Strength Cond. Res., 24(3): 661-667.

11. Moore B.S., J.A. Newsome, P.L. Payne, S. Tianswald (1993) Nursing research: Quality of life and perceived health in the elderly. J. Gerontol. Nurs., 19(11): 7-14.

12. Nelson M.E., W.J. Rejeski, S.N. Blair, P.W. Duncan, J.O. Judge, A.C. King, C.A. Macera, C. CastanedaSceppa (2007) Physical Activity and Public Health in Older Adults: Recommendation from the American College of Sports Medicine and the American Heart Association. Med. Sci. Sports Exerc., 39(8): 435-45.

13. Netz Y., M-J. Wu, B.J. Becker, G. Tenenbaum (2005) Physical activity and psychological well-being in advanced age: a meta-analysis of intervention studies. Psychol. and Aging, 20(2): 272-284.

14. Oken B.S., D. Zajdel, S. Kishiyama, K. Flegal, C. Dehen, M. Haas, D.F. Kraemer, J. Lawrence, J. Leyva (2006) Randomized, controlled, six-month trial of yoga in healthy seniors: effects on cognition and quality of life. Alternative Ther. Health Med., 12(1): 40-47.

15. O'Neill T., D. Marsden, A. Silman, and Group at EVOS (1995) Differences in the characteristics of responders and non-responders in a prevalence survey of vertebral osteoporosis. Osteoporos. Int., 5: 327-334.

16. Pate Russell R., M. Pratt, N. Blair Steven, L. Haskell William, et al. (1995) Physical activity and public health: A recommendation from the Centers for Disease Control and Prevention and the American College of Sports Medicine. JAMA, 273(5): 402.

17. Pavot W., E. Diener (1993) Review of the satisfaction with life scale. Psychol. Assess. 5: 164-172.

18. Piotrowska-Całka E., M. Guszkowska (2007) Effects of Aqua-aerobic on the emotional states of women. Phys. Educ. Sport, 51, 11-14. 
19. Prohaska T., E. Belansky, B. Belza, D. Buchner, V. Marshall, K. McTigue, W. Satariano, S. Wilcox (2006) Physical Activity, Public Health, and Aging: Critical Issues and Research Priorities. J. Gerontol. B Psychol. Sci. Soc. Sci., 61B(5): 267-273.

20. Raphael D., I. Brown, R. Renwick, M. Cava, N. Rein, K. Heathcote (1997) Measuring of quality of life of older persons: A model with implications for community and public health nursing. Int. J. Nursing Studies, 34: 231-239.

21. Rejeski W.J., Brawley L.R., Shumaker S.A. (1996) Physical activity and health related quality of life. Exerc. Sport Sci. Rev., 24: 71-108.

22. Rikli R.E., C. J. Jones (1999) The development and validation of a functional fitness test for communityresiding older adults. J. Aging Phys. Activity, 7: 129-161.

23. Rodrigues B.G.S., S.A. Cader, N.V. Torres, E.M. Oliveira, E.H.M. Dantas (2010) Pilates method in personal autonomy, static balance and quality of life of elderly females. J. Bodywork Mov. Ther., 14(2): 195-202.

24. Salem G.J., J.S. Skinner, W.J. Chodzko-Zajko, D.N. Proctor, S. Fiatarone, A. Maria, T. Minson Christopher, R. Nigg Claudio (2009) Exercise and physical activity for older adults. Med. Sci. Sports Exerc., 41(7): $1510-1530$.
25. Spirduso W.W., D.L. Cronin (2001) Exercise doseresponse effects on quality of life and independent living in older adults. Med. Sci. Sports Exerc., 33: S598-S608.

26. Tróznai T., L. Kullmann (2007) Assesment of the quality of life and the attitudes to ageing of elderly people. LAM-Tudomany, 17(2): 137-143.

27. Vécseyné K.M., B.Zs. Olvasztóné, J. Gangl, J. Bognár (2007) The health-conscious behaviour of people over 55: A preliminary study focusing on gender, marital status, income and educational level. Kalokagathia, 4: 42-50.

28. Waters D., L. Hale (2007) Do Aqua-aerobics improve gait and balance in older people? Int. J. Therapy Rehab., 14(12): 538-43.

29. Wellman N.S., B. Kamp, N.J. Kirk-Sanchez, P.M. Johnson (2007) Eat better and move more: a community-based program designed to improve diets and increase physical activity among older americans. Am. J. Public Health, 97(4): 710-717.

\section{Received 27.06.2012 \\ Accepted 29.09.2013}

(C) University of Physical Education, Warsaw, Poland 